\title{
Aisthesis
}

Firenze University Press

www.fupress.com/aisthesis

OPEN ACCESS

Citation: M. Veleva (2021) Robert Smithson's aesthetics and the future of Earth Art. Aisthesis 14(2): 147-158. doi: 10.36253/Aisthesis-12477

Copyright: (c) $2021 \mathrm{M}$. Veleva. This is an open access, peer-reviewed article published by Firenze University Press (http://www.fupress.com/aisthesis) and distributed under the terms of the Creative Commons Attribution License, which permits unrestricted use, distribution, and reproduction in any medium, provided the original author and source are credited.

Data Availability Statement: All relevant data are within the paper and its Supporting Information files.

Competing Interests: The authors have declared that no competing interests exist.

\section{Robert Smithson's aesthetics and the future of Earth Art}

\author{
Mariya Veleva \\ Departamento de Alemán, Universidad Metropolitana de Ciencias de la Educación, \\ Santiago de Chile \\ mariya.veleva@umce.cl
}

\begin{abstract}
Environmental pollution is a global problem today, and together with urbanization closely intertwined with the current pandemic and the challenges facing humanity. This text, based on Robert Smithson's aesthetic theory and production, intends to show that Earth Art could provide a critical comprehension of industrial culture, could oppose its Gestell (the city may also be seen as Gestell), and sensitize society to the current environmental problems. I also discuss Smithson's multi-stratified art works, his preference for processes over objects and his critical reflection on museums and galleries as closed and traditional spaces. I suggest that Earth Art has the potential to redefine the relationship between outside and inside, optic and haptic, as well between a «distal, disembodied approach» on one hand and «immediate body experience» on the other. It could be developed more intensively in the future, inasmuch it attracts public to open spaces, thus avoiding possible contagion.
\end{abstract}

Keywords: Environmental consciousness, Land art, Robert Smithson, Pollution, Postindustrial landscape, Aesthetic reclamation and recreation.

\section{INTRODUCTION}

Industrialization, dense urbanization and environmental pollution are part of human civilization and directly related to the current pandemic. We can take this crisis as an opportunity to rethink and redefine our relation to the environment and industry, as well to industrial culture (in terms of Adorno); art may help us in this intention.

The statement that art could mediate between industry, ecology and society was developed by Robert Smithson during the 1970s. This text, since it is based on Smithson's aesthetic theory, will follow the evolution of his particular artistic attitude concerning environment, industry and industrial culture. The emphasis is put on his aesthetic sensitization to altered environments through special body experience. I will try to show that this complex body experience was the necessary condition for his ecological turn in his later Earth 
Art projects. Smithson's critical thinking on society and technology as well his interest in entropy, together with this complex body experience of the sites, defined important aspects of his oeuvre and aesthetic theory. I will also stress some of these genuinely realistic, anti-idealistic, anti-romantic, anti-utopian aspects in Smithson's work and thinking, intending to demonstrate how art could help society to recover from its current disease.

\section{SMITHSON'S ARTISTIC DEVELOPMENT IN RELATION TO AN ALTERED ENVIRONMENT}

\subsection{Sensitization through aesthetic experience}

Smithson's artistic fondness was evident from the beginning of his career - starting from his first expedition to the industrial zone of Passaic, New Jersey, which gave birth to the work Monument Passaic, New Jersey - not for unadulterated nature, but for postindustrial landscapes. This led to Smithson's many expeditions during the 1960s. Most of these expeditions resulted in his non-sites that were exhibited in the Dwan Gallery, which means that his aesthetic approach in this stage was still bound to the traditional form of exhibition. ${ }^{1}$ Nevertheless, he insisted on the wholeness of his aesthetic experience, defining the categories of outside-inside in their dialectical relation:

I never thought of isolating my objects in any particular way. Gradually, more and more, I have come to see their relationship to the outside world, and finally when I started making the Nonsites, the dialectic became very strong. These Nonsites became maps that pointed to sites in the world outside the gallery, and a dialectical view began to subsume a purist, abstract tendency. (Smithson [1973]: 311)

During these expeditions Smithson developed an aesthetic taste for the rudimentary quality of stones and ores, for processes and process-based phenomena, but most importantly for the boundlessness of nature; in his exhibitions he tried to

\footnotetext{
${ }^{1}$ Here I am avoiding the opposition between an old and new, which will be explained later.
}

redefine the relation between limits and limitlessness:

The brittleness of the site seemed to swarm around one, causing a sense of displacement. I collected a canvas bag full of slate chips for a small Non-Site. Yet, if art is art it must have limits. How can one contain this «oceanic» site? I have developed the Non-Site, which in a physical way contains the disruption of the site. The container is in a sense a fragment itself, something that could be called a three-dimensional map. [...] [I]t actually exists as a fragment of a greater fragmentation. It is a three-dimensional perspective that has broken away from the whole [...]. There are no mysteries in these vestiges, no traces of an end or a beginning. (Smithson [1968]: 110 -111, emphases mine)

It is interesting that during this time Smithson defined an artist as a site-seer (Smithson [196667]: 340). "The eye is the greatest artist» (Emerson [1981]: 42). The artist suggested «we should begin to develop an art education based on relationship to specific sites. How we see things and places is not a secondary concern, but primary» (Smithson [1979]: 380). Site selection is also a priority: "Site Selection Study" in terms of art is just beginning. [...] One does not impose, but rather exposes the site - be it interior or exterior» (Smithson [1968]: 96).

According to Nietzsche, we impose a certain value just by pointing at something or just by casting a glance at something. Duchamp redefined what art is, in this context. In Objet trouvé and Readymade the objects in themselves bear aesthetic values. The artist no longer needs to create new objects, now the selection of an object is the creative act itself. In this sense every object is potentially an art object. Though, Smithson is not interested in objects, but in processes: "When thing is seen through the consciousness of temporality, it is changed into something that is nothing» (Smithson [1968]: 112).

This is also a radical change in art. The site, the processes, the limitless nature are aesthetically relevant for him. And he as an artist can discover them - with his whole body - and expose them. 
It is interesting in this context that Vattimo translates Heidegger's concept Ge-stell as «imposition» (Vattimo [1987]: 11). Nevertheless, we could translate it from the German verb stellen, i.e. «to position» as (something) imposed, a substantive derived from the past perfect, as «ge-» actually suggests. This aspect of object-hood in Gestell is, in my view, particularly important (Heidegger [1953]: 20-21). When «imposed» is used in this text, it is to be understood also in the sense of Gestell, most broadly as a product of the «technified» or industrialized culture.

Smithson's non-interest in the product/object and the «imposed» but rather in the processes behind is closely related to his aesthetic interpretation of entropy. As we shall see, for him entropy and not poiesis is universal principle for art and nature. This radical aesthetic position questions the tradition, which for millennia has accepted poiesis, or creation, as the fundamental aesthetic law: "Words and rocks contain a language that follows a syntax of splits and ruptures. [...] Poetry being forever lost must submit to its vacuity; it is somehow a product of exhaustion rather than creation. Poetry is always a dying language but never a dead language» (Smithson [1968]: 107, emphasis mine).

Poetry or even art in general, is, just as nature, a «dying language», because their universal principle is entropy and not poiesis. Smithson was convinced of the Earth's inevitable entropic end. $\mathrm{He}$ sees proof of this in geological processes. He assumes that entropy is unavoidable and that our civilization and industry are only temporary phenomena, both under the sign of this universal power. In his opinion Land Art manipulations should follow or undergo the universal entropic processes: "The process behind the making of a storage facility may be viewed in stages, thus constituting a whole «series» of art from the ground up. Land surveying and preliminary building, if isolated into discrete stages, may be viewed as an array of art works that vanish as they develop" (Smithson [1968]: 95, emphasis mine).

Land Art should facilitate the awakening of the aesthetic perception of such natural processes as corrosion, demolition, erosion and crystallization; even more, Land Art should contribute not only to a sober and realistic attitude towards industrial processes such as mining, polluting, drilling, excavating and the consequent landscape transformation, but should also allow their aesthetic appreciation:

Boring, if seen as a discrete step in the development of an entire site, has an esthetic value. [...] The boring, like other works, is becoming more and more important to artists. Pavements, holes, trenches, mounds, heaps, paths, ditches, roads, terraces, etc., all have an esthetic potential. [...] Instead of using a paintbrush to make his art, Robert Morris would like to use a bulldozer. (Smithson [1968]: 95)

All details of the altered landscape, all elements of these industrial ruins have had an aesthetic value for Smithson's artistic eye. However, he experienced the altered landscape aesthetically, with his whole body and not only through his eyes; through his body he perceived nature's immensity and power. In consequence, Smithson developed a peculiar artistic vocabulary, which was expressed later in his sites.

2.2 The human body in Earth Art experience and Smithson's «ecological turn»

The artistic experience is an intense and complex experience of reality where sense perception, reflection, imagination and emotional responsiveness are decisive for the comprehension of its different aspects, including nature's ecological aspects. The body experience is particularly important for grasping ecological values. During his expeditions, Smithson not only perceived the aesthetic qualities of the landscapes with his senses but his whole body was exposed to the influences of the landscape. Peligre Dam in Haiti impacted him because of its scale, measured by his body experience:

The making of artificial lakes with the help of dams, brings into view a vast "garden». For instance, the Peligre Dam in the Republic of Haiti consists of 250- 
foot high concrete buttresses. This massive structure with its artificial cascades and symmetrical layout stands as an immobile facade. It conveys an immense scale and power. By investigating the physical forms of such projects we may gain unexpected esthetic information. I am not concerned here with the original "functions» of such massive projects, but with what they suggest or evoke. (Smithson [1968]: 95-96)

By exploring the landscape aesthetically, the artist was exposed to an integral body experience involving visual perception, olfaction, hearing, thermoception, proprioception (sense of selfmovement and body position), equilibrioception (sense of balance and spatial perception), and thus allowed him to capture wider axiological aspects of the landscape.

Drawing on Merleau Ponty's phenomenological theory of body and perception, White developed the idea that our body experiences guide us to ecological values. The author argues that our comprehension of ecological values is not primarily driven by our rationality but by our body experience:

It is my conviction that ecological values are not cognized first and foremost in "object» cognition but are given originally in terms of lived body experience. Human beings are "rational animals», and it is precisely in the experience of our animality, i.e. of our vital and bodily being, that we attain our first access to understanding ecological values. (White [2007]: 177, emphasis mine)

It must be mentioned here that although Smithson was sensitive to ecological aspects of reality, there was something more - a real and axiological conflict - that awakened his ecological consciousness and attitude. In Smithson's first Sites, contamination was viewed as an aesthetically relevant process. In the Pures from 1969 - Asphalt Rundown, Glue Pour, and Concrete Pour - entropic forces, artistic processes, as well industrial practices, substances and pollution are combined into one. The Pours can be regarded as evidence that Smithson had no ecological concerns at this time, but his aggressive approach to the landscape would later become the reason for his reorientation and his search for specific artistic balance between industrial damage, art, and social environmental consciousness.

After producing Glue Pour in Vancouver in 1969, Smithson found a possible location near it for his project on a series of hypothetical continents associated with broken glass. The authorities initially approved the project and submitted the prospective location, Miami Islet, as a gift. However, public opinion shifted; some environmentally active circles vehemently opposed the execution of the project on the island and the permission for its use was withdrawn. Smithson was involved in real social and political conflict.

Consequently, the artist comprehended the axiological conflict, which emerged in this Broken Glasses project: aesthetic values conflicted with ecological values. This caused him not only to rethink the relationship between these aspects of reality, with which he was always in touch, but provoked an immediate attitude change regarding the environment:

Smithson concurred that despite the low risk of harm, the glass project should not be done as proposed. In its stead, he subsequently submitted the Miami Islet project as a broken de-architectural concrete earthwork - concrete habitats so as "to encourage wildlife to visit and use the island as a nesting and breeding ground», adding «especially cormorants that need to rest on a dry level». The project was now to be considered "a monument to ecology». (Graziani [2004]: 108)

In this new proposal we can see Smithson's philosophical «retorsion», in the sense of Verwindung (or postmodern brake), i.e., convalescence and recovery from the illness of the modern industrial culture. Smithson's artistic position regarding ecological aspects of the environment is clearly defined in his next projects, Spiral Jetty and Broken Circle / Spiral Hill. He later used these earth sculptures as an example for many subsequent proposals. They became crucial for his portfolio, particularly in relation to his ecological appeal. However, some authors like Hobbs 
could not recognize Smithson's ecological concern behind his postmodern break to art as land reclamation:

This interest in post-industrial Sites as a form of Nonsite led Smithson in the early seventies to conceive of land reclamation as a new art form. His concern was never ecological; Smithson was an artist fascinated with the look of pollution. [...] Feeling that polluted and strip-mined areas were eminently picturesque, he proposed art projects to such corporations as Hanna Coal in Ohio and Kennecott Copper in Utah, with the hope of gaining access to the giant earth-moving equipment owned by these companies. (Hobbs [1982]: 17, emphasis mine)

Although Smithson was impressed by contamination in a particular aesthetic way, after the dialectical «retorsion» in Vancouver he was exclusively concerned with the opportunity to raise awareness for the damaged landscapes - namely through aesthetically recycling them - both in industrial companies and the greater public: "Across the country there are many mining areas, disused quarries, and polluted lakes and rivers. One practical solution for the utilization of such devastated places would be land and water recycling in terms of "earth art"» (Smithson [1979]: 376). And further: «Such devastated places as strip mines could be recycled in terms of earth art» (Smithson [1979]: 379).

He also understood art's didactical function to mediate between industry and society: "Art can become a resource, that mediates between ecologist and industrialist. Ecology and industry are not one-way streets, rather they should be crossroads. Art can help to provide the needed dialectic between them» (Smithson [1979]: 376).

Smithson's art also has the function to expose «the process behind» (Smithson [1968]: 95), the «blind progress» (Smithson [1979]: 380) at the back of «the imposed»: «The world needs coal and highways, but we do not need the results of strip-mining or highway trusts. Economics, when abstracted from the world, is blind to natural processes» (Smithson [1979]: 376, emphasis mine). And further:
Art on this scale should be supported directly by industry, not only private art sponsorships. Art would then become a necessary resource, and not an isolated luxury. The artist must overcome the inequities that come in a wake of blind progress [emphasis mine]. Those in economic power should not thwart such necessary enterprises. [...] Artists should not be cheated out of doing their work, or forced to exist in the isolation of «art worlds». There should be artist-consultant in every major industry in America. (Smithson [1979]: 380)

Unfortunately, Smithson's increasing sensitivity to ecological problems and his ideas about dialectical transformation of industry-affected sites through art could not find the expected support, and most of his proposals were not executed. Smithson died in an accident at age 35.

\subsection{The ideology and aesthetic of «the imposed»}

White suggests that [...] if one lives in a civilization where body experiences and body practices are not conducive to the experience of one's own vital values, one will quite likely fail to recognize and appreciate the values of the environment» (White [2007]: 179-180).

Indeed, it seems that big cities, small square apartments and mass culture made us insensitive to nature. We have developed a certain «value blindness» or «axiological blindness» (Von Hildebrand [1922]: 44) towards ecological values, by limiting our taste more and more clearly to values imposed by the «industrial culture».

Smithson was critical of the industrial culture, the ideology of consumerism, the ideals of technology and the values and practices in art based on them. He reproached that Pop Art and Minimal Art are bound by the ideology of technology and industry, to the ideals of the timeless and the unchangeable. What is imposed on us in this predominantly visual culture is the static and polished face, or the last pronounced symbol of industry, mostly presented as its final product, as an «ideal< object; but behind it there is its invisible, destructive body, with its processes and 
rejects. Smithson criticized the «illusory» aesthetics and ethics of «the imposed», of Gestell:

Only commodities can afford such illusionist values; for instance, soap is 99/100\% pure, beer has more spirit in it, and dog food is ideal; all and all this means such values are worthless. As the cloying effect of such "values» wears off, one perceives the "facts» of the outer edge, the flat surface, the banal, the empty, the cool, blank after blank; in other words, that infinitesimal condition known as entropy. (Smithson [1966]: 13)

Regarding this entropy of information, or entropy of truth, history, and memory, Baudrillard speaks in his book The illusion of the end (1992). The ideology and aesthetics of technology and industry, which we know from advertising and which has also penetrated the arts, turns out to be a simulacrum. For the artist, technological values such as durability or eternity are utopian. There is nothing timeless in nature; entropy, destruction, corrosion and weathering are, by contrast, typical natural processes. "Nature is never finished» (Smithson [1972]: 155), it is continuously in progress, it is open and has no limits. Earth Art works as vanishing objects, as genuinely open artworks, (in terms of Umberto Eco) oppose the Gestell.

Land Art works are not objects in the same sense as objects of art which are exposed in art galleries or museums. Smithson's criticism of museums as a traditional exhibition center should be understood in this context. Museums are also an ideal, isolated, arranged space, something that contradicts reality; indeed, something alien and hostile to art, which should be realistic, authentic and open to society. Smithson called museums cultural prisons where art is locked up:

Museums, like asylums and jails, have wards and cells - in other words, neutral rooms called "galleries». A work of art when placed in a gallery loses its charge, and becomes a portable object or surface disengaged from the outside world. A vacant white room with lights is still a submission to the neutral. Works of art seen in such spaces seem to be going through a kind of esthetic convalescence. They are looked upon as so many inanimate invalids, waiting for critics to pronounce them curable or incurable. (Smithson [1972]: 154)

Smithson propagated an expansion of art from beyond the borders of the city, of the studio, by saying: "Even the most advanced tools and machines are made of the raw matter of the earth. [...] The tools of art have too long been confined to "the studio"» (Smithson [1968]: 101-102). Not only industrial products, but also artworks, galleries, museums, and cities turn out to be Gestell, since they are closed systems, which impose a certain way of life: "The city gives the illusion that earth does not exists. Heizer calls his earth projects "The alternative to the absolute city system" " (Smithson [1968]: 102).

When we look further, we can see that in this industrial culture the human body could also be quantified and finally transformed into Gestell. Humanity is on the road to "trans-humanism», and Smithson already witnessed the problems related to this transformation of the human body and consciousness when involved in industrial processes: "The artist and the miner must become conscious of themselves as natural agents. When the miner loses consciousness of what he is doing through the abstractions of technology, he cannot cope with his own inherent nature and external nature» (Smithson [1979]: 379).

This cements the fact that this «old normal» led us to a dead end: namely to a climate catastrophe, a pandemic and to a deeper crisis of humanity. Now if we ask for a new normal, for new aesthetic concepts and theories, as well for new forms of art, we may be going the wrong way. If we follow Vattimo and his notion of «weak thought», there were attempts in the history of philosophy to overcome the problems (or the «cultural diseases») of modernity, however, inasmuch as «going beyond» (überwinden) forms part of modernity in its tendency to surpass the old again and again, it repeats and confirms its own essence and would necessarily fail. The repetition of these attempts ad infinitum and the 
despair of the self are described by Kierkegaard in his work Mortal disease. In Vattimo's view only Nietzsche manages to break free from modernism entirely, accepting its weakening, or in Smithson's terms, its entropic tendency, instead of trying to overcome it. Nietzsche's (and later Heidegger's) concept of Verwindung has the meaning "to recover" from disease, and "contains no notion of dialectical sublimation (Aufhebung) nor of "leaving behind", which characterizes the connection we have with a past that no longer has anything to say to us» (Vattimo [1987]: 7).

Can we recover from the disease of our modern culture only by accepting, recognizing and radicalizing its «entropic» forces? Another alternative to recover from the disease is through the imposition of a strong repressive, closed, and totalitarian system; this resembles Heidegger's Verhängnis, the metaphysical essence of the Westculture, which claims rational "planetary governance» (Heidegger [1936-1946]: 75). Indeed, the only phenomenon in Nature, which opposes entropy is information (essentially metaphysical) since it organizes or creates order. «The eternal war» between information and entropy affects everything existing, "from atoms to economies» (Hidalgo [2015]: X). Maybe now we are experiencing «the great reset» (Schwab et al. [2020]), the transition from blind to considerably rational, «purposeful capitalism» (Mazzucato [2019]), which will be «more sustainable» but will imply also «less sovereignty» (Vilimsky [2009]); a global Gestell imposed from the Industry 4.0, paradoxically to save the planet.

Smithson has already grasped the power of entropy in his oeuvre that may be seen as an alternative to Gestell, to Simulacra, to Lethea. In the following, I hope to demonstrate this by showing that his works are multi-stratified superimpositions, where every perceivable stratum has also meaning, where conflict and hidden processes or taboos are not suppressed or excluded, but exposed in dialectical manner (i.e. displaced) in reference to other processes and meanings.
2.4 Smithson's multi-stratified oeuvre as alternative to the «imposed» and to Simulacra

In the following, I will discuss the «displacement» in Smithson's work. This concept has at least three meanings in his oeuvre: firstly, in opposition to Freud's notion, it could be understood as dialectical exposing of the hidden, forgotten, or forbidden industrial and cultural processes, however not by reducing but by increasing the tension or even by causing disruption to the experience of the viewer. Secondly, it refers to the feeling of displacement when the body is exposed to the site. This is Smithson's «oceanic feeling» or «sense of cosmic rupture» as his alternative to the objectcognition. Thirdly, we can speak about many «displacements» in Smithson's works, where every displacement, with a reference to some axiological or existential sphere, has built a visual and intelligible stratum. Thece meanings are also emphasized in Ann Reynolds' work Robert Smithson: Learning from New Jersey and Elsewhere.

Industrial processes and devastation are taboo in the industrial culture. Smithson performed many «displacements» in his works, trying to expose these processes, to make them transparent and visible. In these displacements we can see the same figure of logical «retorsion»; they are in this context symptoms of Verwindung, i.e. recovery from the industrial disease. These displacements are not explicit, unambiguous, «linear» or one-dimensional, on the contrary, they are very dialectical, multidimensional, representing the «strata» of the consciousness, the «strata» of the reality, in their dialog: «By refusing "technological miracles" the artist begins to know the corroded moments, the carboniferous states of thought, the shrinkage of mental mud, the geologic chaos-in the strata of esthetic consciousness» (Smithson [1968]: 107), and much more, in their physical interaction in and throughout the artist's body: "The strata of the Earth is a jumbled museum» (Smithson [1968]: 110).

Smithson's works are extremely complicated «montages» of his body experiences. Reynolds writes that Smithson experimented with different «frameworks» in order to organize in dialectical 
manner implicating conflict, his "perceptual experience of the site» (Reynolds [2004]: 222). The artist created complex works, as media, as montage and as content. They refer to different existential and axiological spheres; they consist of different interrelated strata. We can comprehend the didactic mission of Smithson's works, their resistance to the imposed and to the industrial culture, only if we also understand their multi-stratified essence.

Adorno criticized industrial culture with its tendency to transform the cultural objects in Gestell: «The culture industry has three crucial effects on cultural objects. Firstly, it makes from them commodities. Secondly, it fragments these objects. Thirdly, it makes them so easily assimilative that they cannot generate a real experience» (Stojanov 2012, 127). Thus, according to Adorno, «the fragmentation of cultural objects means that their elements are abstracted from the structural logic of those objects in their historical genesis» (Stojanov 2012 , 127). Not only is the imposed product of industry abstracted from the processes which built it, but also the objects of art: «The function of the warden-curator is to separate art from the rest of society. [...] Once the work of art is totally neutralized, ineffective, abstracted, safe, and politically lobotomized it is ready to be consumed by society. All is reduced to visual fodder and transportable merchandise. Innovations are allowed only if they support this kind of confinement» (Smithson [1972]: 154-155). This fragmentation, states Stojanov:

[S]hould be seen as the central mechanism of the assimilative preparation of these objects; a preparation that consists in breaking down their original resistance and their independence from the subjects who try to appropriate these objects. Yet, according to Adorno, cultural objects can generate a real experience and initiate a process of Bildung only on the condition they remain sovereign objects that resist their assimilation in pre-given subjective schemes of reality perception. (Stojanov 2012, 127-128)

Smithson's works, inasmuch as they are complicated "displacements», difficult to decipher, have the potential to question the already exist- ing interpretation of reality, to provoke conflict or resistance in the person experiencing them and, in this sense, to educate. Reynolds explains in this context that Smithson's works produced oft "physical and psychological tensions» or even «discomfort» (Reynolds [2004]: 196).

The artist, repeatedly, never thought to isolate his works "in any particular way» (Smithson [1973]: 311). They have many strata and are also strata from larger strata, they only exist in their sometimes non (chrono-)logical, irrational, conflictive interrelatedness to other objects and sites:

All of Smithson's displacements are in some sense stills - arrested, partial, and dislocated events that depend on other images and contexts for signification. Like Eisenstein's montage, they are also superimpositions. The splitting and superimposition in Smithson's displacements occur simultaneously - voids filled, frames occupied - and conflict produces their meaning. (Reynolds [2004]: 226)

Smithson's works are always «fragmentation of a greater fragmentation». The artist used such «doublings», as Reynolds states - referring to his proposal Towards the Development of a Cinema Cavern or the Movie Goer as Spelunker - also to expose the taboos: "Such doubling, in terms of making and then viewing the film at the site, would have structurally echoed the taboo against women entering the mine that Smithson discussed with Wheeler: «It's a very strong taboo. I read somewhere there is a strong feeling that, in the primitive sense, the tube is like a vagina, kind of like a Freudian protectiveness» (Reynolds [2004]: 227). These «doublings» appear also when two displacements have taken place, when they overlap, leaving two often conflictive strata in the artwork; in this sense they are also denominated «superimpositions». "Doublings» appear also in relation to the different references and spheres of reality.

We see that Smithson's works are an alternative to the imposed, to the lobotomized commodities; they are antagonists to Gestell, inasmuch as they are multidimensional, complicated and full of conflicts. They are postmodern «superimpositions» of 
the imposed, since they are exposing the hidden processes and principles that built it. In such dialectical, critical «doubling», or «retorsion» we can see Smithson's effort to overcome modern industrial culture, to recover from its disease.

The concept of "superimposition» is used often in photography, cartography and cinematography. Reynolds, in analyzing Smithson's works, refers to Eisenstein's understanding of superimposition as a complex montage of images, which also implies conflict (Reynolds [2004]: 224). Special effects of movement, depth, as well as other illusions can be created through superimposition, however the author stresses that «Superimposition can also produce visual - and aural - conflict» (Reynolds [2004]: 223), and Smithson used it to produce a conflict:

Smithson demonstrated this by superimposing mirrored chambers over the two pictures on the stereoscope card in a plan of a simple box stereoscope [...]. The conflict between mind and body, conditioned expectation and reality, that the Enantiomorphic Chambers generates opens up a visible gap between the physiological aspects of vision-its binocular structure-and the experiences they produce. (Reynolds [2004]: 223)

Every stratum constructs the plasticity and the meaning of the work. Conflict has an important function in the whole. Popper in his book The open society and its enemies (1945) places emphasis on the importance of conflict in the "open society», i.e. non-totalitarian society. Conflict has an important function in art, if we understand an artwork as a process and even more, in Smithson's terms, as a dialectical process, as position, as negation and then as superimposition, manifested in a series of displacements. The final product of industry and culture - the imposed - consists of only one simple "position $<$. There is no tension or conflict in «the imposed»; it is easy to be consumed, comprehended and assimilated. With all these "displacements», conflicts and «superimpositions» Smithson questions the «object-cognition», the imposed with its limits, and his purpose is to provoke this feeling of «displacement». This is also valid for the movie Spiral Jetty, where the artist tried to represent the aesthetic impact of the site's scale on his body and mind: «Sky and earth, filmic and "natural" reflections intermittently collapse together, causing the jetty to momentarily disappear behind these flashes of reflected light» (Reynolds [2004]: 225).

Summarizing, Smithson's works are complicated narratives. Each work is in its essence a «story» (in German: Geschichte) built from different strata. The German word Geschichte refers to Schichten, in the sense of geological strata, and also signifies «history». The verb schichten means «stratify», and Geschichte is the substantive originated from the past perfect, as "ge- indicates. Geschichte is the stratified past time, where each stratum has meaning, and where all strata together build a substrate for the new upcoming events.

Jean Baudrillard paints in his work The Illusion of the End (1992) an almost apocalyptic image, a fatal end of the postmodern era, in which history disappears in the flow of information broadcast every day by the media. In an increasingly accelerated transmission of news and news events, the story loses its substance, or using Smithson's terminology we could say its substratum. The individual no longer remembers the events of yesterday, of last year, s/he loses her/his memory, and the reality loses its depth. In this sense Smithson's works are true stories, are Geschichten; they may be seen as an alternative to the flow of information (metaphorically, to the entropy of the information, of truth and memory, or to Lethea), as true A-Lethea, or «knowledge». This also cements their potential to educate.

\section{CLOSING REMARKS}

We can only imagine what kind of art works could be developed in the current conditions, where social interaction and the analog reality in general became taboo. Perhaps such dialectical forms of artistic experience will be developed, which relate to outside and inside, real and virtual, giving birth to interesting aesthetic forms and 
categories. Three-dimensional, virtual art works in the sense of «three-dimensional maps» could refer to some "oceanic» site or real experience; with such «fragments» from the immense nature, artists could intervene in urban landscapes and question the everyday perception. Earth Art works could be developed on grand scale: «Remote places such as Pine Barrens of New Jersey and the frozen wastes of the North and South poles could be coordinated by art forms that would use the actual land as a medium» (Smithson [1968]: 95). Such coordinated efforts between artists could be developed on a grand magnitude, to defend nature. Here will be only summarized how Earth Art could awaken society to the dangers of the industrial culture and its Gestell, and what sources it opens to convalesce the current disease.

As was already emphasized, in Earth Art the observer is no longer merely an observer but a coexperiencer; s/he is in the work of art, involved with her/his body perceptions in a unique experience of reality. S/he is exposed to the environment, not the art object to her/him. By aesthetically sensitizing the observer and engaging her/his entire body, Earth Art could be a mediator of environmental values, could awaken awareness to ecology, could provoke the feeling of immense, infinite, process-based and open-ended reality and help to overcome the "object-cognition». In this context Richard Long's works are an alternative to the «diseases» of the big cities; they invite us to hear nature, to hear our own voice, to meditate, and in this sense to free us from the «imposed», allowing us to discover and adopt more authentic values. To revise the imposed and often blindly adopted values critically means to make first step towards authenticity, which is profoundly related to our feeling of happiness and fulfilment.

Adorno argues that «the modern cultural industry denies the individual's access to the world and prevents the process of self-development, that is, of Bildung» (Stojanov 2012, 126). Thus, Earth Art could also be in the future an important didactic resource that teaches us how to resist cultural industry. The individual can discover through Earth Art the risks and possibilities of the current reality, can reach critical orientation and authentic happiness in a society. Art becomes didactic by exposing the current time: "The artist must come out of the isolation of galleries and museums and provide a concrete consciousness for the present as it really exists, and not simply present abstractions or utopias» (Smithson [1979]: 379).

In the last decade, digital reality appears and consumes our consciousness instead of the analog reality. The current pandemic accelerated the process of digitalization, which already affected all spheres of life, including museums, galleries and art in general. We can speak about the «digital coup» we are experiencing now. On one hand, digitalization presents new opportunities to save the environment through the optimization of processes and technologies. On the other hand, it contains risks, one of which is human isolation from the environment and consequently alienation from nature. When our consciousness is involved in a virtual reality, we lose contact mentally and physically with our natural, material environment. This could also lead to a posterior loss of sensitivity and to an axiological blindness regarding the environment. Such digital artworks may appear in the future, engaging us to experience them with our entirely body as Gesamtkunstwerk. Inasmuch as a Land Art work is essentially Gesamtkunstwerk because of this integral experience of the body it evokes, it could prevent or help to overcome the negative effects of the digital «simulacra» on our perception of ecological values. How will everything change after this «digital coup», taking into account that physical space is now stigmatized and displaced (in Freudian sense), and our freedom in physical space is reduced? We must consider that new structures will be build up in virtual space; it is a new market with new scope. One remembers how cities established next to a market or to a port in the Middle Ages, how the arts developed in the palace, in the cathedral and in other public spaces. We can only imagine how social structures, the arts and indeed the whole culture will change after this shift into digital space, in the context of Industry 4.0. Again, Earth Art offers an alternative. 


\section{REFERENCES}

Adorno, T.W., 1991: Culture Industry Reconsidered, in Bernstein, J. M. (ed.), The Culture Industry: Selected Essays on Mass Culture, transl. by A. G. Rabinbach, Routledge, London, pp. 98-106.

Baudrillard, J., 1981: Simulacra and Simulation, transl. by S. F. Glaser, University of Michigan Press, Ann Arbor MI, 1994.

Baudrillard, J., 1992: The illusion of the end, transl. by C. Turner, Stanford University Press, Redwood City CA, 1994.

Dreher, T., 1992: Robert Smithson: Land Reclamation and the Sublime, "Artefactum" 45, pp. 26-30.

Eco, U., 1962: The Open Work, transl. by A. Cancogni, Harvard University Press, Cambridge MA, 1989.

Graziani, R., 2004: Robert Smithson and the American Landscape, Cambridge University Press, New York .

Heidegger, M., 1936-1946: Die Überwindung der Metaphysik (1936-1946), in Herrmann, F.W. (ed.), Vorträge und Aufsätze. Gesamtausgabe, Band VIII, Klostermann, Frankfurt a.M., 2000, pp. 67-99.

Heidegger, M., 1953: Die Frage nach der Technik, in Herrmann, F.-W. (ed.), Vorträge und Aufsätze. Gesamtausgabe, Band 8, Verlag Vittorio Klostermann, Frankfurt am Main, 2000, pp. 5-37.

Hidalgo, C., 2015: Why Information Grows: The Evolution of Order, from Atoms to Economies, Basic Books, New York.

Hobbs, R., 1981: Robert Smithson: Sculpture, Cornell University Press, Ithaca.

Hobbs, R., 1982: Robert Smithson: A Retrospective View. Exhibition catalogue, Wilhelm Lehmbruck Museum der Stadt Duisburg and Herbert F. Johnson Museum of Art Cornell University, Ithaca .

Kastner, J., Wallis, B. (eds.), 2010: Land and Environmental Art (1st Edition), Phaidon, New York.

Linsley, R., 2004. Robert Smithson and Art After Pollock, in Smithson, R., \& Arnold, G., (ed.),
Robert Smithson in Vancouver: A fragment of a greater fragmentation. Vancouver Art Gallery, pp. 68-74.

Mazzucato, M., 2019: How to create a more purposeful capitalism. World Economic Forum, URL: https://www.weforum.org/agenda/2019/01/purposeful-capitalism-economicsmariana-mazzucato/

Popper, K.R., 1945: The Open Society and Its Enemies, Princeton University Press, Princeton NJ, 2020.

Reynolds, A., 2004: Robert Smithson: Learning from New Jersey and Elsewhere, MIT Press, Cambridge MA.

Schwab, K., Malleret, T., 2020: COVID-19: The Great Reset, ISBN Agentur Schweiz, Zürich.

Smithson, R., 1966: Entropy and the new monuments, in Flam, J. (ed.), Robert Smithson: The Collected Writings, The Documents of Twentieth-Century Art, University of California Press, Oakland CA, 1996, pp. 10-24.

Smithson, R., 1966-67: The artist as site-seer; or, a dintorphic essay, in Robert Smithson: The Collected Writings, Berkeley CA, 1996, pp. 340346.

Smithson, R., 1968: A thing is a hole in thing it is not, in Robert Smithson: The Collected Writings, Berkeley CA, 1996, pp. 95-97.

Smithson, R., 1968: A sedimentation of the mind: Earth projects, in Robert Smithson: The Collected Writings, Berkeley CA, 1996, pp. 100-114.

Smithson, R., 1972: Cultural confinement, in Robert Smithson: The Collected Writings, Berkeley CA, 1996, pp. 154-157.

Smithson, R., 1973: Robert Smithson on Duchamp/ Moira Roth, in Robert Smithson: The Collected Writings, Berkeley CA, 1996, pp. 310-313.

Smithson, R., 1979: Untitled (1971), in Robert Smithson: The Collected Writings, Berkeley CA, 1996, p.: 376.

Smithson, R., 1979: Untitled (1972), in Robert Smithson: The Collected Writings, Berkeley CA, 1996, p.: 379.

Smithson, R., 1979: Proposal (1972), in Robert Smithson: The Collected Writings, Berkeley CA, 1996, pp. 379-380. 
Stojanov, K., 2012: Theodor W. Adorno-Education as social critique, in Siljander, P., Kivelä, A., Sutinen, A. (eds.), Theories of Bildung and Growth: Connections and Controversies Between Continental Educational Thinking and American Pragmatism, Sense Publishers, Rotterdam, Boston MA, Taipei, pp. 125-135. https://www.springer.com/gp/ book/9789462090316

Vattimo, G., 1985: The End of Modernity: Nihilism and Hermeneutics in Postmodern Culture (Revised Edition), The Johns Hopkins University Press, Baltimore MD, 1988.

Vattimo, G., 1987: "Verwindung". Nihilism and the Postmodern in Philosophy. "SubStance" 16 (2), pp. 7-17, doi:10.2307/3685157, URL: https:// www.jstor.org/stable/3685157

Vattimo, G., 1996: Belief, transl. by L. D’Isanto, D. Webb, Polity Press, Boston MA, 1999.

Vilimsky, S., 2009: 2089/J (XXIV. GP)-Teilnahme am «Bilderberg-Treffen» vom 14.-17. Mai, im Nafsika Astir Palace Hotel, in Vouliagmeni (in der Nähe von Athen), Griechenland. (s. f.). Recovered 14.03. 2021,: https://www.parlament.gv.at/PAKT/VHG/XXIV/J/J_02089/ index.shtml

Von Hildebrand, D., 1922: Sittlichkeit und ethische Werterkenntnis: eine Untersuchung über ethische Strukturprobleme. 3. durchgesehene Aufl., Patris Verlag, Vallendar-Schönstatt, 1982.

White, J.R., 2006: Ecological value cognition and the American capitalist ethos, "Environmental Philosophy" 3 (2), pp. 44-51.

White, J.R., 2007: Lived Body and Ecological Value Cognition, in Cataldi, S., Hamrick, W. (eds.) Merleau-Ponty and Environmental Philosophy: Dwelling on the Landscapes of Thought, Suny Press, New York, pp. 177-189. 